\title{
MÁQUINA DE MOER GENTE: O PROBLEMA DA RELAÇÃO AMBÍGUA ENTRE DIREITO E VIOLÊNCIA
}

\author{
A MACHINE FOR GRINDING PEOPLE: THE PROBLEM OF THE AMBIGUOUS \\ RELATION BETWEEN LAW AND VIOLENCE
}

\author{
José Antonio Rego Magalhães* \\ Juliana Neuenschwander Magalhães ${ }^{* *}$
}

\begin{abstract}
RESUMO
O objetivo deste artigo é expor, a partir principalmente da obra de Walter Benjamin e de Jacques Derrida, uma certa ambiguidade na relação entre os conceitos de direito e de violência, e colocá-la como problema, ainda que a solução desse problema não esteja no escopo deste artigo, precisando ser tratada alhures. Em primeiro lugar, apresentaremos o conceito de violência como problemático, distinguindo-o de outros como poder e força. Com base em Benjamin, apresentaremos a distinção entre meios e fins conforme pensada pelo positivismo e pelo jusnaturalismo, bem como a distinção estabelecida pelo autor entre a violência instituinte e a violência mantenedora do direito. Exemplificaremos essas questões mediante uma breve discussão da instituição policial e do instituto dos “autos de resistência”. A seguir, exporemos as razões pelas quais Benjamin acaba por condenar o poder jurídico, reconhecendo nele uma circularidade viciosa, a partir da qual esse poder se mostra como uma manifestação imediata da violência, que o autor chama de violência "mítica". Terminaremos com uma breve sugestão quanto à possibilidade de pensar-se uma solução para o problema apresentado.
\end{abstract}

PALAVRAS-CHAVE

Jacques Derrida. Walter Benjamin. Violência. Autos de resistência.

\begin{abstract}
The goal of this paper is to show, mainly through the work of Walter Benjamin and Jacques Derrida, a certain ambiguity in the relation between the concepts of law and violence, and to pose it as a problem, yet the solution to this problem is not to be reached in this paper, needing to be developed elsewhere. First we will present the concept of violence as problematic, distinguishing it from other issues such as power and force. Through Benjamin, we will present the distinction between means and ends as thought by legal positivism and natural law, as well as the distinction established by the author between the violence that institutes law and the one which maintains it. We will exemplify those questions through a brief discussion of the police institution and of the "autos de resistência". Next, we will show the reasons why Benjamin ends up condemning legal power, seeing in it a vicious circularity, in light of which it shows itself as an immediate manifestation of violence, called by the author "mythic" violence. We will end this paper with a brief suggestion about the possibility of thinking a solution to the established problem.
\end{abstract}

\footnotetext{
* Mestre pela Faculdade Nacional de Direito da Universidade Federal do Rio de Janeiro (UFRJ) (Rio de Janeiro, RJ, Brasil). E-mail: jamagalhaes22@gmail.com

** Doutora em Direito pela Universidade Federal de Minas Gerais (UFMG) e pela Universidade de Salento, Itália. Professora Associada na UFRJ. Pesquisadora 1D no CNPq (Rio de Janeiro, RJ, Brasil). E-mail: jneuewander@yahoo.com.br
} 


\section{KEYWORDS}

Jacques Derrida. Walter Benjamin. Violence. Autos de resistência.

\section{INTRODUÇÃO}

Este artigo faz parte de uma pesquisa mais ampla sobre a dinâmica das relações entre direito e violência. Dinâmica na medida em que essas relações são tematizadas aqui como complexas e instáveis. A natureza mais precisa dessa instabilidade é o que procuraremos explicar, tomando como ponto de partida a segunda parte do livro Força de Lei, de Jacques Derrida, intitulada "Prenome de Benjamin”. Trata-se de um ponto de partida em si já instável, na medida em que o texto de Derrida não se propõe a fundar nenhum conceito próprio, mas parte de uma leitura de outro texto, "Para uma Crítica da Violência”, de Walter Benjamin. Este texto, por sua vez, já é bastante instável em si mesmo. Será preciso começar por Benjamin, e aqui ele tomará a maior parte da nossa atenção. Ao mesmo tempo, não traçaremos uma distinção exata entre o momento da análise da crítica da violência benjaminiana e o da análise da leitura proposta por Derrida. Isso porque a distinção entre a desconstrução operada na leitura de Derrida e aquela que já se opera no próprio texto de Benjamin não é claramente definível.

Começaremos por uma exposição dos principais elementos da crítica da violência de Benjamin, já os colocando em contato com os comentários de Derrida e outros, como Giorgio Agamben e Judith Butler. O que será discutido no presente artigo, acima de tudo, são os aspectos violentos do direito, ligados à sua possibilidade de instituir-se, de determinar-se e de aplicar-se sobre sujeitos. Este trabalho, assim, se desenvolverá como a apresentação de um problema, de uma situação problemática inerente à relação entre direito e violência. Esse problema não será, aqui, resolvido, mas sim exposto na sua natureza aporética, restando a outros trabalhos - nossos ou de outrem - a tarefa de solucioná-lo.

\section{O PROBLEMA DA NOÇÃO DE VIOLÊNCIA}

O ensaio de Benjamin se desenvolve em uma crítica da violência. Crítica, Derrida (2005, p. 79) aponta, não no sentido de uma simples "avaliação negativa, rejeição ou condenação [...] da violência”, mas sim de uma investigação que “se dá os meios” de julgar a violência. Judith Butler (2006, p. 201) explica que uma crítica da violência, no caso de Benjamin, "é uma pesquisa sobre as condições da violência, mas é também uma interrogação sobre como a violência é circunscrita de antemão pelas questões que colocamos sobre ela.” Assim, Benjamin analisará primeiramente as 
formas usuais de avaliação da violência e, constatando a sua insuficiência, buscará recolocar a questão da violência em uma nova configuração.

Benjamin (2011, p. 121) começa estabelecendo que uma crítica da violência, da forma como ele a compreende, só pode ser efetuada a partir da relação entre violência, direito e justiça. Afinal, “o conceito de violência pertence à ordem simbólica do direito, da política e da moral - de todas as formas de autoridade e de autorização, ou pelo menos de pretensão à autoridade” (DERRIDA, 2005, p. 79). Derrida nos lembra que a palavra “Gewalt”, em torno da qual circula o ensaio de Benjamin, não pode ser traduzida apenas como “violência”, mas também “força legítima, violência autorizada, poder legal, como quando falamos de Staatsgewalt, o poder do Estado”. A ambiguidade carregada por esse termo - com seu aspecto institucional e seu aspecto radicalmente anti-institucional - ocupará este artigo inteiro. Não obstante, pode-se dizer que, em ambos os sentidos da palavra, a definição de “Gewalt” se dá por relação à esfera da legalidade e da justiça. No sentido de poder instituído como titular legítimo da violência, a definição da Gewalt é coextensiva à própria esfera do direito. Já como violência no sentido mais estrito, a Gewalt nunca se define em função própria, e sim em contraposição àquilo que está instituído como legítimo. Aparece como violência, neste segundo sentido, precisamente aquilo que excede e ameaça o poder (Gewalt) do Estado e do direito.

Poderíamos adotar a formulação de David Lapoujade (2015, p. 79), segundo a qual "a violência não existe”, isto é, ela não tem uma essência em si mesma. Para o autor, “a violência é sempre qualificada, nunca qualquer; sempre já tomada na percepção de um campo social que a codifica ou a qualifica, mas que sobretudo a distribui”. Isto é, dito de outro modo, sempre definida a partir da sua relação com essa “distribuição da violência social a que se dá o nome de direito" (LAPOUJADE, 2015, p. 80). Lapoujade (2015, p. 79) explica, em uma formulação bem ao estilo de Derrida, que as definições da violência são "sempre já políticas e estratégicas”. Nenhum contexto fixo de interpretação pode garantir a compreensão da violência para além de uma situação contingente. Isso, é claro, pode ser dito sobre o sentido estrito da palavra "Gewalt”, como violência exterior à esfera do direito, que, contudo, se define em relação a ela. A “Gewalt” como poder legítimo, por outro lado, é facilmente identificável como tal.

Aqui faz-se interessante um exercício classificatório na linha do realizado por Hannah Arendt no seu Da Violência. A classificação adotada pela autora, a partir de Alexandre Passerin d'Entrèves, distingue entre força, poder e violência, e pode servir aqui como ponto de partida. Arendt (1970), seguindo d'Entrèves, aponta que a força, a partir do momento que é qualificada ou institucionalizada por meio do direito, deixa de ser propriamente força, tornando-se poder. A força propriamente dita estaria restrita, para Arendt (1970, p. 44) à “energia liberada pelos movimentos 
físicos ou sociais", que ela exemplifica nas expressões "forças da natureza” e "força das circunstâncias”. Essa definição de força parece vaga o suficiente para servir aos propósitos deste trabalho, levando-se em conta que, no seu contexto, a noção de força deverá carregar as conotações particulares dadas a ela na obra de Derrida. Em Força de Lei, Derrida (2005, p. 20) explica que, em seus textos, “o recurso à palavra ‘força’ é ao mesmo tempo muito frequente, [...] decisivo em lugares estratégicos”, mas sempre cuidadoso e acompanhado de ressalvas. Para Derrida, essa palavra traz o "risco de um conceito obscuro, substancialista”, além do "risco de uma autorização dada à força violenta, injusta, sem regra, arbitrária”. Contra esse risco de uma concepção substancialista, Derrida sublinha o que é para ele o “caráter diferencial da força”:

[Nos meus textos], trata-se sempre de força diferencial, diferença como diferença de força [...]; trata-se sempre da relação entre a força e a forma, entre a força e a significação; tratase sempre de força performativa, força ilocucionária ou perlocucionária, de força persuasiva ou retórica, de afirmação de assinatura, mas também e sobretudo de todas as situações paradoxais onde a maior força e a maior fraqueza se intercambiam estranhamente. (DERRIDA, 2005, p. 20)

A força então, como a violência, não tem essência própria. “Quando dizemos que a força é diferencial, o que estamos dizendo é que a força não é algo” (DERRIDA, 2002, p. 35). “A força é basicamente um nome muito comum para designar aquilo para o que não temos um conceito capaz de ser claramente expresso em um dado código filosófico”. "Na filosofia”, explica Derrida, “o valor da força sempre esteve em representar aquilo que resistia à análise conceitual. Daí o risco.” Se a força é a diferencialidade, então ela é também a escrita, essa "rede de marcas que são codificáveis [...] em iterabilidade”. Derrida ressalta que a força, como não é alguma coisa, não é poder. O poder é algo, mas não a força. Esta “está sempre inscrita em um espaço onde um ardil, [uma manha, um artifício...] é possível fazendo do mais fraco o mais forte.” Essa propriedade anti-institucional da força pode, segundo Derrida, “ser traduzida em termos políticos”.

Por tudo isso, faz-se necessário um cuidado especial sempre que se trata da noção de força. Em "Force et Signification”, Derrida (1967b, p. 44) denuncia o formalismo estruturalista pelo risco que este apresenta de “esconder o sentido pelo ato mesmo através do qual ele é descoberto”. Para o autor, “compreender a estrutura de um tornar-se [devenir], a forma de uma força, é perder o sentido ao ganhá-lo”. Em outras palavras, a forma fechada que se substitui à força nunca é capaz de traduzila completamente. “A qualidade do acontecimento e da força é ofuscada pelo próprio sentido”. Derrida (1967b, p. 45) explica que dizer que a força é a origem por trás das formas não é dizer nada. Sempre que a força é dita, expressa em uma linguagem, ela já não é mais propriamente força, e sim forma. Dizer, então, que a força é a origem da forma não passa de uma maneira oblíqua de referir-se à “impotência da linguagem de sair de si mesma para dizer a sua origem”. A força, para Derrida, é “o 
outro da linguagem” e, ao mesmo tempo, condição de possibilidade de toda linguagem.

Ao mesmo tempo - e aqui é que a presente organização classificatória começa a se complicar -, Derrida (2005, p. 17) chama atenção, em Força de Lei, para o fato de que não há como pensar o direito instituído e aplicável senão relacionando-o à detenção de uma certa força. O autor toma como ponto de partida a expressão "to enforce the law" que, em inglês, significa aplicar a lei. Ao ser traduzida assim, porém, a expressão "perde essa alusão direta, literal à força que vem [...] nos lembrar que o direito é sempre uma força autorizada, uma força que se justifica ou que é justificada para aplicar-se”. Derrida faz referência a Kant para dizer que "a enforceability não é uma possibilidade exterior ou secundária [...] ao direito". Ela indica a força “implicada no próprio conceito" de direito. Assim, a distinção entre o poder como força institucionalizada e a força como pura diferença nem sempre se mantém estável.

Cabe enfatizar, como Derrida (1967b) o faz constantemente, que não se trata de uma simples inversão da lógica tradicional, privilegiando a força sobre a forma. Precisamos das formas do direito. Sem elas, não há possibilidade de justiça (DERRIDA, 2005). O comentário de Derrida (1967b, p. 48), no final de "Force et Signification", sobre uma citação de Flaubert é esclarecedor nesse sentido. Flaubert, o escritor famoso por buscar a perfeição da frase, queixa-se que não há formas suficientes. “Como entender isso?” - pergunta Derrida. Como uma celebração da força que excede e resiste a toda forma? De maneira alguma. Para Derrida, o lamento de Flaubert traduz "uma religião da obra como forma”, uma apologia do esforço interminável de traduzir para o mundo finito das formas o mundo infinito do irrepresentável. De maneira análoga, as formas do direito nunca são suficientes, mas sempre necessárias. A luta pela justiça está sempre em um esforço de traduzir, nas formas jurídicas, aquilo que as excede.

Assim, temos o poder como força instituída e a força como força excedente a toda instituição, e ao mesmo tempo um certo grau de contaminação entre as duas noções. Resta definir o lugar da noção de violência nessa economia. Arendt (1970, p. 45) escreve que ela "se distingue pelo seu caráter instrumental”. Isto é, a violência (que, como visto, não tem essência em si mesma) define-se sempre como instrumento para algo além dela. Apenas um meio, e nunca um fim em si mesmo, pode ser considerado violento. Assim, a questão da violência é sempre uma questão de quais as situações em que um meio é considerado ou como meio legítimo, ou como voltado a fins justos. Essa definição servirá ao presente trabalho, na medida em que ela se aproxima do ponto de partida adotado por Benjamin, que começa sua análise do problema da violência em torno do par meios/fins. Ao mesmo tempo, será visto que a crítica benjaminiana acaba por exceder e deslocar essa oposição, enquanto Da Violência “continuou preso à abordagem tradicional da violência como mero instrumento, como 
meio para um fim exterior” (DUARTE, 2015, p. 73).

Com efeito, Agamben (2004) interpreta o ensaio de Benjamin como voltado, acima de tudo, a garantir a possibilidade de uma violência absolutamente externa ao direito, que já não se defina em função do par meios/fins, e que seja puramente desconstituinte. No entendimento de Butler (2006, p. 201), a crítica de Benjamin coloca duas questões principais sobre as relações entre violência e direito. A primeira questão é sobre como a violência (ou poder) do direito se torna possível, isto é, quais as condições de possibilidade dessa violência e quais as suas relações com as condições de possibilidade do direito. Benjamin estaria, nessa primeira fase, preocupado em entender a natureza das relações entre o direito e a violência, e como essa natureza determina a relação entre o direito e seus sujeitos. Já a segunda questão investiga a possibilidade de um outro tipo de violência que não apenas possa ser invocado contra a violência coercitiva do direito, mas que seja, em si, não coercitivo e não violento. No presente artigo, ocupar-nos-emos da primeira questão, ficando a segunda para outro momento. O que é que torna possível, então, a violência do direito como poder?

\section{A RELAÇÃO ENTRE MEIOS E FINS SEGUNDO O JUSNATURALISMO E O POSITIVISMO}

Foi visto que, para Benjamin (2011), a crítica da violência deve dar-se a partir das esferas do direito e da justiça. Para o autor, isso significa que essa crítica se articula em torno da distinção entre meios e fins. Esse, para ele, é o par fundamental ao redor do qual se organiza a esfera jurídica. Afinal, pode-se dizer que a questão do direito e da justiça é sempre uma questão sobre quais os meios legítimos para atingir certos fins, ou quais os fins justos que legitimam certos meios. O conceito de violência só pode emergir dessa esfera, na medida em que um ato só é percebido como violento ou não violento a partir da sua relação com alguma concepção de legitimidade ou de justiça.

Benjamin (2011, p. 122) passa, então, a distinguir o tratamento dado pelo positivismo e pelo jusnaturalismo à questão da relação entre violência, direito e justiça, ou seja, da relação entre meios e fins. O autor quer demonstrar que ambas as escolas compartilham um "dogma fundamental" ambas presumem a ligação necessária entre a justiça dos fins e a justificação dos meios. Sabe-se que, para o jusnaturalismo, o direito instituído só tem validade quando corresponde à justiça natural. Assim, o uso de qualquer meio está justificado, mesmo que entre em conflito com o direito, desde que voltado a fins justos. A justiça dos fins, sendo assim, fundamenta a legitimidade dos meios. Já para o positivismo, o direito é simplesmente aquilo que historicamente foi instituído, e um meio será legítimo sempre que for assim estabelecido por esse direito, não importando os fins a que se dirija. Nesse caso, é a legitimidade dos meios que garante a justiça dos fins. Benjamin aponta, porém, que 
tanto no caso do jusnaturalismo quanto no do positivismo há a presunção de que a justificação dos fins e a legitimidade dos meios possam ser, de alguma forma, derivadas uma da outra. A diferença entre as duas posições está apenas no sentido dessa derivação, enquanto o dogma fundamental é mantido.

Assim, Benjamin (2011) argumenta que tanto o ponto de vista positivista quanto o jusnaturalista deixam de lado a questão essencial, que para ele seria a de julgar a violência em si mesma, como princípio, isto é, como meio e independentemente dos seus fins. Benjamin escolhe, ainda assim, tomar como ponto de partida a visão positivista, já que ela permite a distinção entre dois tipos de violência: de um lado a violência sancionada (historicamente reconhecida, legítima, que poderíamos chamar de poder) e, de outro, a violência em sentido estrito, não sancionada. Essa distinção servirá de base para que Benjamin comece a articular seu próprio aparato crítico, ainda que depois ele deva abandoná-la.

\section{VIOLÊNCIA INSTITUINTE E VIOLÊNCIA MANTENEDORA DO DIREITO}

Benjamin (2011, p. 126) passa, então, a debruçar-se sobre certas "relações de direito" observadas na Europa de sua época do Entreguerras, a fim de desenvolver mais claramente a distinção entre as diferentes funções que a violência pode assumir, segundo a relação entre meios e fins. Ele analisa o direito à legítima defesa, o uso do castigo físico na educação, a figura do grande criminoso, o direito de greve e a greve geral revolucionária, o direito de guerra, o serviço militar obrigatório, a pena de morte, a polícia, o parlamentarismo, a diplomacia, os tribunais de arbitragem, etc. Dessas análises, emergem algumas distinções conceituais importantes e complicadas, como aquelas entre violência que instaura o direito e violência que mantém o direito, entre greve geral política e greve geral proletária, bem como entre a violência que ele chama “mítica” e a que ele chama "divina”.

Para Benjamin (2011, p. 136), a violência pensada como meio voltado a um fim pode ser “ou instauradora [instituinte, fundadora, rechtsetzende] ou mantenedora [conservadora, rechtserhaltende] do direito”. Há uma violência inicial, na situação revolucionária em que uma ordem jurídica é formada, e essa violência fundadora gera, daí por diante, a possibilidade de uma violência mantenedora do direito, sancionada e administrativa. Butler (2006, p. 201) explica que a violência que mantém o direito "é exercida pelos tribunais e [...] pela polícia e representa esforços repetidos e institucionalizados para garantir que o direito continue a ser cogente [binding] sobre a população que ele governa”, essa violência “representa as formas diárias através das quais o direito se faz aplicar [is made to be binding] de novo e de novo sobre os sujeitos”. Já a violência que funda o direito é “o que 
é feito quando uma entidade política [polity] nasce [comes into being], e o direito é feito”. Butler ressalta, por outro lado, que essa forma de violência "também pode ser uma prerrogativa exercida pelos militares em ações coercitivas inovadoras voltadas a lidar com populações insubmissas”.

Derrida (2005, p. 93), no que tange a essa distinção entre dois tipos de violência, anuncia que, “para além do propósito explícito de Benjamin”, vai propor uma interpretação segundo a qual a violência instituinte do direito passa a “envolver [envelopper]” a violência mantenedora do direito. Para Derrida (2005, p. 97), Benjamin se dedica a um “movimento ambíguo e laborioso para salvar a qualquer preço uma correlação sem a qual seu projeto poderia desmoronar”, sendo que, a despeito desse esforço, “a distinção entre as duas violências [...] será muito difícil de traçar, fundar ou conservar”. Não acompanharemos Derrida nessa interpretação dos propósitos de Benjamin, não apenas porque, em outros momentos, Derrida (2005, p. 129) admite que Benjamin "reconhece de certa forma [a] lei da iterabilidade que faz com que a violência fundadora esteja sempre representada na violência conservadora”, mas por dois outros motivos mais relevantes. O primeiro é que se torna impossível, sem reconhecer no texto de Benjamin a implicação mútua entre a violência instituinte e a violência mantenedora do direito, fazer sentido de outras oposições conceituais que mais tarde serão fundamentais não apenas para o seu projeto, mas para a leitura de Derrida, em especial aquela entre violência “mítica” e violência “divina”. Isso deverá ficar claro mais adiante. O segundo motivo é que, no próprio texto de Benjamin, essa contaminação é acusada de forma tão frontal que se torna difícil imaginar que Derrida não a tenha percebido.

Ela se mostra gradualmente. Primeiro, ao discutir a pena de morte, Benjamin (2011, p. 134) aponta que “o seu sentido não é o de punir a infração do direito, mas de instaurar um novo direito”. A imposição da pena de morte, que em princípio deveria ser entendida como a aplicação de um direito já instituído, aparece como violência instituinte. Para Benjamin, já começa a mostrar-se, nessa contaminação entre os dois tipos de violência, “algo de podre no direito”. Esse “algo de podre” também se faz presente, de forma ainda mais grave, na instituição da polícia moderna. Benjamin (2011, p. 135) reconhece tratar-se, em primeiro lugar, de uma violência voltada a fins previamente estabelecidos pelo direito, ou seja, uma violência do tipo conservador do direito. Ele aponta, porém, que a polícia tem “a competência simultânea para ampliar o alcance desses fins de direito”. "O infame de uma tal instituição”, escreve Benjamin (2011, p. 135, grifo nosso), “reside no fato de que nela está suspensa a separação entre a violência que instaura o direito e a violência que o mantém”. Afinal, em razão da urgência frente à qual a polícia sempre deve agir, ela concentra, em muitos casos, o poder de decidir sobre o uso da própria força, sem referência ao poder legislativo ou ao judiciário. Daí as suas características de discricionariedade e autoexecutoriedade, sem falar na necessidade dos seus

Revista da Faculdade de Direito - UFPR, Curitiba, vol. 61, n. 3, set./dez. 2016, p. 299 - 321 
agentes de interpretar o direito de forma imediata a cada vez que o aplicam. Derrida (2005, p. 102) aponta que a polícia é, desse ponto de vista, “estruturalmente repugnante”, na medida em que "sua ausência de limite não vem somente de uma tecnologia de vigilância e repressão que se desenvolvia já, em 1921, de forma inquietante”, mas que a polícia de certo modo “é o Estado”, no sentido de que ela já não se contenta em aplicar o direito pela força [enforce], mas sim o inventa, ao publicar decretos e ao intervir, toda vez que uma situação jurídica não está clara - isto é, sempre e cada vez mais - a pretexto de garantir a segurança.

Talvez, no Brasil, o instituto que mais traduz esse lado assustador do direito e da polícia, do direito como polícia e da polícia como direito, das instituições que regulam e distribuem o uso legítimo da violência em nossa sociedade, sejam os chamados “autos de resistência”. Por meio desse instituto, nossa polícia tem confiscado a vida de habitantes das periferias das grandes cidades, acima de tudo jovens negros e pobres, não na forma de casos excepcionais, mas de modo sistemático, regulado, institucionalizadoํ․ Essa “figura atípica” (FERREIRA, 2013, p. 32) do nosso ordenamento, oriunda da ditadura militar, cria, para todos os efeitos práticos, uma captura do corpo e da vida do indivíduo pela violência do direito. Sua forma de funcionamento é a seguinte. Quando um agente da polícia mata alguém em serviço, ele deve lavrar esse auto, assinado por duas testemunhas, evitando assim ser autuado em flagrante delito. Na prática, os autos são lavrados e os inquéritos abertos, mas os inquéritos, via de regra, são inócuos, já que não é realizada investigação, e costumam ser ouvidos geralmente apenas os próprios policiais que assinaram o auto. Se Benjamin via "algo de podre no direito” a partir do momento em que este alcançava, mediante a pena de morte, o poder sobre a vida do indivíduo, e identificava no poder disforme da polícia a pior face desse direito, os "autos de resistência” concentram e exibem todos os elementos dessa engrenagem assustadora. Em um caso como esse, o texto legal torna-se indistinto das formas discursivas e ideológicas que condicionam a sua aplicação, de tal modo que a instituição policial passa a operar como um dispositivo (AGAMBEN, 2009) que distingue entre corpos não matáveis e matáveis (os chamados “vagabundos”), segundo critérios abertamente ligados à classe social e à etnia. Isso é verificado a partir de indícios de execuções sumárias, como tiros à queima-roupa, além de tiros pelas costas, na nuca ou vários tiros direcionados à cabeça (FERREIRA, 2013).

Na sua recente passagem pelo Brasil, em que fez a conferência magna do I Seminário Queer, em São Paulo, Judith Butler (2015) chamou atenção para a gravidade desse problema, justamente

\footnotetext{
${ }^{1}$ Dados da Anistia Internacional indicam que, no ano de 2012, 30 mil assassinatos no Brasil tiveram como vítima jovens, dos quais 77\% eram negros. Segundo esses dados, "matou-se mais no Brasil [entre 2004 e 2007] do que nas doze maiores zonas de guerra do mundo” (PELLEGRINI, 2014).
} 
como forma de passar a discutir a questão do direito, da violência e da polícia em Benjamin. Reproduzo uma parte da sua fala:

É sem dúvida importante para nós que vivemos nos Estados Unidos entender que, mesmo enquanto nos opomos à morte de pessoas negras nas ruas, e nos organizamos sob a rubrica de "black lives matter", no Brasil vocês têm convivido com o fato de que mil ou mais pessoas por ano são mortas pela polícia, e menos de um por cento dessas mortes são levadas a juízo. A polícia não é processada, não importa que crimes ela cometa. [...] Isso nos leva a perguntar não apenas no interesse de quem existe o direito, mas inclusive se o direito não perdeu seu poder vinculante. (BUTLER, 2015)

Butler (2015) explica que, conforme Benjamin argumentou na “Crítica da Violência”, a polícia não apenas aplica, mas faz o direito, “já que, no momento em que a polícia decide invocar o direito, ela revigora sua operação, e quando ela vê uma operação e não a chama de crime, então a situação não é tratada como um crime, e o direito não é aplicado”. Sobre quando os próprios agentes policiais são autores do fato, Butler ironiza: “Como eles poderiam cometer um crime? Eles são a polícia!” Ela explica, assim, a forma como a violência que institui e a que mantém o direito acabam se confundindo na ação da polícia, o que dá a ela uma espécie de poder soberano. “A cada vez que uma prisão é feita, uma multidão é dispersada, um conjunto de pessoas é cercado ou detido, a polícia efetivamente diz ‘isto é poder soberano legítimo’ e, ao praticar esse ato de fala, ela captura o sujeito² na força da lei”. Com base nesses argumentos, Butler afirma que "a polícia faz poder soberano no local [police do sovereign power on the spot]. Sua ação, portanto, não tem freios.

Câmeras e celulares têm repetidamente flagrado atos de arbitrariedade e violência assustadores perpetrados por essa polícia, tanto mais assustadores pela convicção que mostram, por parte dos seus agentes, da impunidade. Trata-se de uma instituição que tem como prática tirar selfies ao lado de manifestantes verdes-e-amarelos enquanto trata estudantes, professores e movimentos sociais à base de balas de borracha e gás lacrimogêneo; dar passe livre aos que pedem intervenção militar e intervenção militar aos que pedem passe livre. Isto é, que exerce poder decisório, pela força, sobre a liberdade política dos indivíduos. Não é por nada que a explosão do número dos participantes nas manifestações de junho de 2013 teve como estopim a violência policial contra manifestantes, transmitida a contragosto pela televisão e a todo vapor pelas redes sociais (GOHN, 2014). Essa violência policial ${ }^{3}$ - que finalmente "deixa de atingir apenas jovens pobres da periferia e passa a

\footnotetext{
${ }^{2}$ A questão de como o sujeito é capturado e determinado pelo direito será discutida mais adiante.

3 Túlio Kahn (2014, p. 128), sociólogo especialista na questão policial, embora em seu artigo explique e em alguma medida justifique a ação da polícia durante os acontecimentos de junho de 2013, arrola, com conhecimento técnico, uma série de falhas que contribuem para a violência dessa ação. Assim, fica claro que a violência policial no Brasil é também, em grande medida, relacionada a uma falta de investimentos que poderiam torná-la mais racional. "Caberia à Secretaria Nacional de Segurança Pública (Senasp), com base na experiência internacional, estabelecer detalhadamente as condições e os limites para o uso de equipamento não letal (ou menos letal) nas manifestações”, explica Kahn. "Na ausência de regras claras, o que vimos foi o uso indiscriminado desses meios em quase todos os protestos”. Ademais, uma série de
} 
assolar a classe média branca nas principais avenidas do país” (KAHN, 2014, p. 128) - parece ter um apelo muito forte aos afetos sociais, ainda que as razões desse apelo sejam inconscientes. Não parece absurdo pensar que ele se deva à forma como a polícia, acima de qualquer outra instituição, traduz essa confusão explosiva entre instituição e manutenção do direito, feita máquina de moer gente que gira em seu próprio eixo. Benjamin (2011, p. 136) diz da polícia moderna que ela "não tem figura”, isto é, sua estrutura institucional, que deveria dar conta da sua legitimidade, é disforme. Seu estatuto é incompreensível. Afinal, se "na monarquia a polícia representava diretamente o poder do soberano, que reúne em si a plenitude do poder legislativo e executivo” (BENJAMIN, 2001, p. 136), nas democracias contemporâneas a sua existência se mostra "a maior deformação da violência que se possa conceber”, afinal ela concentra, em um sistema cuja legitimidade está fundada sobre a separação dos poderes, funções legislativas, judiciárias e executivas.

Derrida (2005, p. 102) parece observar que, na análise de Benjamin, "essa ausência de fronteira entre as duas violências, essa contaminação entre fundação e conservação” é “a ignomínia [das Schmackvolle] da polícia”. Ainda assim, é ao discutir a questão dos contratos que Benjamin parece se aproximar mais de Derrida no que tange à inscrição da violência instituinte do direito em todos seus atos de manutenção. Essa violência, embora procure apagar-se a partir do momento em que coloca a máquina do direito em andamento, permanece, segundo Benjamin (2011, p. 137), “representada” em todo contrato, na medida em que "o poder [macht] que garante o contrato de direito é, por sua vez, de origem violenta, mesmo que esse poder não tenha sido introduzido no contrato pela violência”. É precisamente ao acusar essa iterabilidade (DERRIDA, 1972) que deve repetir o ato performativo da fundação do direito em toda aplicação (isto é, em cada instância da sua manutenção) que Derrida (2005) afirma a impossibilidade de uma distinção rigorosa entre a violência que institui e aquela que mantém o direito. $\mathrm{O}$ autor aponta uma espécie de paradoxo no que tange à violência instituinte do direito. Por um lado, essa violência parece mais vulnerável à crítica do que a violência mantenedora, já que, diferentemente desta, ela não conta com nenhum direito anterior sobre o qual fundar sua legitimidade. Por outro lado, ela parece, pelo mesmo motivo, menos vulnerável, ou mesmo invulnerável à crítica, na medida em que a sua legitimidade se funda nela mesma, não sendo possível “fazê-la comparecer perante a instituição de nenhum direito preexistente” (DERRIDA, 2005, p. 98). Para Derrida, é esse “instante revolucionário”, em que “a fundação de um novo direito joga, por assim

irregularidades mais ou menos notórias observadas nas manifestações: "Policiais sem tarjeta de identificação; uso de equipamento com data de validade vencida; detenção ilegal de manifestantes portando vinagre; falta de comunicação entre comando e tropa; uso de armas não letais sem condições de visibilidade, distância mínima, mirando abaixo dos joelhos, como preveem os manuais, etc." Kahn chama atenção para a escassez de investimentos voltados à "falta de equipamento, treinamento e doutrina para garantir pacificamente o direito de reunião e manifestação”, ao passo que há recursos para "a renovação dos estoques de bombas de efeito moral e de balas de borracha”. 
dizer, com algo de um direito anterior que ela estende, radicaliza, deforma, metaforiza ou metonimiza”, que "apaga ou confunde [brouille] a distinção pura e simples entre fundação e conservação", na medida em que "inscreve a iterabilidade na originalidade”. A iterabilidade das marcas que formam o direito significa não apenas que cada instância de manutenção deve remeter-se à violência instituinte, mas também que mesmo esta não é pura, e sim contaminada por formas anteriores com cujos recursos joga.

\section{O DIREITO COMO VIOLÊNCIA}

Foi discutido até aqui como, no ensaio de Benjamin (2011), a violência que institui o direito dá origem a uma segunda violência, voltada a mantê-lo. Essa violência se exerceria para reiterar, em cada contexto subsequente, a cogência do direito sobre os seus sujeitos. Viu-se, porém, que já no texto de Benjamin, e mais explicitamente na leitura proposta por Derrida, há uma contaminação mútua entre essas duas violências. Contaminação que, trazida à tona, dá a perceber “o infame” da instituição jurídica - “algo de podre” no coração do direito. Em instituições como a pena de morte, a polícia e o poder militar, a distinção entre violência instituinte e violência mantenedora do direito é suspensa, de modo que a possibilidade de distinguir entre fins legais e fins arbitrariamente afirmados desaparece. Torna-se impossível, nesses casos, separar o direito legítimo da violência arbitrária ou da pura força.

Foi visto ainda que a contaminação em questão tende a estender-se para além dessas instituições, na medida em que toda aplicação do direito depende, a cada nova instância, da reafirmação da violência instituinte da qual sua legitimidade é derivada. Isso significa que, para além do que se tem usualmente por direito positivo, o direito é informado por uma dimensão não escrita que condiciona, porém, a legibilidade e a aplicabilidade do direito posto. Essa força "simbólica” de manutenção do direito pode mesmo, no limite, encontrar outras formas de agir que não as juridicamente legitimadas. Há, como explica Žižek (2008), uma violência “objetiva simbólica” que, no cotidiano, esconde a violência "sistêmica” e mostra como violência "subjetiva” aquilo que a perturba. Após todas as observações desenvolvidas até aqui, a vida do direito se mostra cada vez mais sob a aparência inquietante de um círculo vicioso. A possibilidade da transformação do direito tornase difícil de pensar. Nesta seção, procurarei explicar o juízo crítico que Benjamin faz sobre essa violência do direito, que ele chama de violência “mítica”, e em contraposição à qual ele procura garantir uma violência absolutamente externa ao direito, dita “divina”. 


\subsection{A VIOLÊNCIA DO DIREITO COMO MANIFESTAÇÃO IMEDIATA}

A violência "mítica” surge a partir da desestabilização do conceito de violência instituinte do direito estabelecido pelo próprio Benjamin, no que pode ser visto como uma instância da “autodesconstrução” que Derrida aponta no ensaio. A distinção entre a violência instituinte e a violência mantenedora do direito, conforme pensada por Benjamin (2011), depende da possibilidade de que esta última possa justificar-se, enquanto meio violento, não em função dos fins aos quais ela se volta, mas por ter sido historicamente legitimada como meio, isto é, do seu "pedigree” histórico 4 . Disso depende a sua "não violência” no sentido da legitimidade. O que estabelece, por sua vez, esses meios legítimos, é a violência instituinte do direito, de modo que esta não pode ser, em si mesma, um meio legítimo. Ela se coloca como legítima apenas em função do seu próprio fim, isto é, o de instituir a sua própria legitimidade. Coloca-se, portanto, como fim em si mesma. Ao perceber isso, Benjamin está, ao seu modo, acusando a tautologia performativa discutida por Derrida (2005) em Força de Lei, o aspecto "místico" da fundação do direito. O autor argumenta que a violência que institui o direito teria uma "função dupla” (BENJAMIN, 2011, p. 148), no sentido de que aquilo que ela almeja como fim, usando a violência como meio, é a sua própria constituição como poder instituinte. “A instauração constitui a violência em violência instauradora do direito”, não ao instituir um “fim livre e independente da violência”, mas “um fim necessário e intimamente ligado a ela”. Nenhum fim (de justiça, por exemplo) para além da sua própria manutenção anima essa violência instituinte, que instaura a si mesma como fim de direito "sob o nome de poder [Macht]”. “A instauração do direito”, afirma Benjamin (2011, p. 148), “é instauração do poder e, enquanto tal, um ato de manifestação imediata da violência”.

Que Benjamin se refira à violência instituinte do direito como manifestação imediata merece pausa, pois marca um ponto de inflexão no ensaio. Até esse ponto, o autor havia mostrado que a violência do direito, instituinte ou mantenedora, só poderia ser pensada a partir da relação entre fins e meios, sendo a violência sempre meio para um fim. Esse é o caso tanto para o jusnaturalismo quanto para o positivismo, e Benjamin, como foi visto, toma o segundo como ponto de partida. No esquema positivista, a violência pode ser julgada legítima por referência a um critério historicamente instituído no ato da fundação do direito. Aferida a legitimidade de uma violência, quaisquer fins a que ela se volte estão justificados. Até aqui, a violência nunca pode ser considerada “imediata”, mas sempre meio para um fim. Na medida, porém, em que a violência instituinte do direito não deriva sua

\footnotetext{
${ }^{4}$ A expressão "tese do pedigree” tornou-se conhecida a partir do debate entre H. L. A. Hart (1994) e Ronald Dworkin (1978) sobre os limites do conceito de direito. Trata-se da tese positivista segundo a qual a distinção entre o que é direito e o que não é se dá em função de um critério de origem histórica. A expressão, é claro, é anacrônica em relação ao texto de Benjamin, mas me parece que seja cabível.
} 
legitimidade histórica senão dela mesma, há como que um curto-circuito na relação de legitimação e justificação entre fins e meios, que afeta não apenas a legitimidade da violência instituinte, mas também a da mantenedora do direito. A rigor, a separação entre as duas, que era regida pelo par meios/fins, torna-se insustentável. O par meios/fins aparece como uma ficção interna à concepção que o direito faz de si mesmo, técnica interpretativa instituída juntamente ao direito. Mostra-se, então, a "indecidibilidade última de todos os problemas de direito", na medida em que nunca se pode determinar rigorosamente a legitimidade ou ilegitimidade da violência. Disso decorre que a violência do direito, instituinte ou mantenedora, já não aparece como meio voltado a fins, e sim manifesta-se de forma imediata como violência.

Gostaria de argumentar que é justamente a partir da contaminação entre a violência instituinte e a mantenedora do direito - já presente, portanto, em seu ensaio - que Benjamin termina por rejeitar a violência do direito, buscando uma alternativa a ela. "Em todo o campo das forças [Gewalten] levadas em consideração pelo direito natural ou pelo direito positivo”, argumenta Benjamin (2011, p. 145), nenhuma escapa a essa “grave problemática”. Daí a necessidade de superarse o "dogma básico" comum às duas filosofias, segundo o qual os meios podem derivar sua legitimidade dos fins e os fins podem derivar sua justificação dos meios. Superado esse “dogma” interno à estrutura do direito, este já não se mostra como uma dialética entre duas violências legítimas ou justificadas, regida em torno do par meios/fins, mas como uma violência indistinta que "se impõe à maneira do destino” (BENJAMIN, 2011, p. 146). Creio que não seria errado dizer que, enquanto de um ponto de vista interno à instituição do direito, a partir do qual a ligação entre meios e fins é operante, pode-se ver o direito como legítimo, de um outro ponto de vista, que não reconheça esse “dogma” interno, o direito se mostra como uma violência que não é nem meio nem fim, mas que se manifesta como uma violência ligada ao destino. Benjamin (2011, p. 155) escreve que "um olhar dirigido apenas para as coisas mais próximas perceberá, quando muito, o movimento dialético de altos e baixos nas configurações da violência instauradora e mantenedora do direito”. Por isso o autor precisa imaginar um ponto de vista externo ao direito, externo às teorias positivistas e jusnaturalistas que o pensam segundo a lei interna dos seus meios, da relação entre meios e fins, para efetuar uma crítica contundente da violência do direito, bem como para pensar a sua superação.

\subsection{VIOLÊNCIA “MÍTICA”}

Benjamin (2011, p. 146) chama essa violência - a violência do direito na medida em que nela se confundem instauração e manutenção - de “violência mítica” porque a relaciona, entre outras 
coisas, à ordem do destino e à “cólera dos deuses”. Ela é da ordem do destino porque sua força cogente não se fundamenta em nada para além de si mesma, da mesma forma como não faria sentido perguntar sobre o destino por que ele é o destino. Não é da essência do destino que ele deva justificar-se. Butler (2006, p. 202) explica que “o destino pertence ao mundo helênico do mito”. Segundo a autora, Benjamin deixa claro que a violência que institui o direito é da ordem do destino, na medida em que “a fundação do direito [the making of law] cria as condições para que procedimentos justificatórios e deliberações possam ter lugar”. Da mesma forma, “a violência conservadora do direito seria um “subproduto" da violência que o instaura, sendo o modelo do destino o mecanismo pelo qual essa violência opera. Sendo assim, as duas violências que formam o direito podem ser compreendidas como ligadas ao mito e à tradição grega. Derrida (2005, p. 79), de forma semelhante, refere-se à violência “mítica” de Benjamin como "grega, me parece [grecque, me semble-t-il]”. Para Benjamin (2011, p. 146), essa violência "grega” estaria ainda ligada à cólera ${ }^{5}$ como violência que não se relaciona como meio a um fim determinado, mas apenas mostra a si mesma enquanto violência. Quem externa colericamente uma violência não pretende com isso nada além de externá-la. A violência da cólera "não é meio, e sim manifestação", escreve Benjamin (2011, p. 146). Ele explica que "a violência mítica em sua forma arquetípica” está na "manifestação dos deuses”. É a lenda grega de Níobe que fornece o seu exemplo.

Segundo a lenda, Níobe, uma mortal, decide gabar-se de ser mais fértil do que Leto, a deusa da fertilidade, já que tinha quatorze filhos, enquanto Leto tinha apenas dois. A deusa não acha graça na impertinência de Níobe e manda seus filhos, Apolo e Artêmis, para que a castiguem, matando com flechas seus quatorze filhos. Níobe, por sua vez, é transformada em pedra, mas as suas lágrimas pela morte dos filhos permanecem correndo eternamente dos seus olhos. Butler (2006, p. 208) analisa essa lenda em maior detalhe, ligando a "violência” mítica à origem da culpa e do sujeito. Para a autora, a cólera dos deuses “age performativamente para marcar e transformar Níobe, estabelecendo-a como sujeito culpado”. A petrificação serviria, assim, como metáfora para a estruturação do sujeito como tal, vivente transformado em sujeito pela ação da violência “mítica”. “A transformação de Níobe em um sujeito de direito”, afirma Butler (2006, p. 208), “envolve recolocar a violência infligida pelo

\footnotetext{
${ }^{5}$ Frédéric Gros (2015) estabelece uma distinção entre três tipos de violência, sendo uma delas a cólera. Para o autor, há em primeiro lugar uma violência "intransitiva”, que tem um fim em si mesma e se satisfaz na destruição (talvez esta pudesse ser relacionada à violência “divina” que será discutida mais a fundo no capítulo a seguir). Em segundo lugar, há a cólera como exasperação face a uma realidade, indignação, rancor, reivindicação de justiça. Há, em terceiro lugar, o ódio (na palavra francesa, "haine") como desejo de destruir o outro porque sua existência representa uma negação da nossa. Finalmente, há a crueldade ou o sadismo quando se toma prazer pelo sofrimento do outro. A definição de cólera fornecida por Gros pode nos ser interessante, mas com a ressalva de que a justiça ressentida a que ele faz referência não se identifica com a justiça em sentido estrito, que Benjamin chamará de "divina”, mas com a justiça "dos homens", a exemplo do justiciamento.
} 
destino como uma violência decorrente das suas próprias ações, e pela qual ela, como sujeito, assume responsabilidade direta”. A violência "mítica” não somente funda performativamente o direito, mas também torna possível as relações de culpa e retribuição em seu interior, cancelando, porém, a violência instituinte que as determina em primeiro lugar. Se a pedra representa a captura do vivente na condição de sujeito de direito, as lágrimas simbolizam a culpa que a acompanha. Daí que a violência “mítica”, para Benjamin (2011, p. 15), além de ser instauradora do direito, “ameaçadora” e “sangrenta”, é aquela que "traz simultaneamente a culpa e a expiação”. As condições para que possa se falar de qualquer culpa ou da sua expiação são estabelecidas pela instituição do direito, na medida em que o vivente é capturado por ela como sujeito juridicamente responsável.

Em seu ensaio “Fundar a violência: uma mitologia?”, Lapoujade (2015, p. 85) faz uma discussão do mito como "relato das fundações” ligado à justificação. O autor pergunta como se pode dizer de um ato violento que ele é legítimo, enquanto outro ato, às vezes da mesma natureza, será considerado ilegítimo. Essa função de “explicar, legitimar ou justificar os atos de violência” pertence, para Lapoujade (2015, p. 80), aos discursos e, é claro, aos discursos internos ao direito. “Justificar deve ser compreendido como um verbo milagroso”, explica o autor, já que “ele transforma em justiça aquilo que ele explica”. Essa justificação milagrosa, “mística” dos atos de violência estaria ligada à ordem do mito, não porque misticismo e mitologia sejam da mesma ordem, mas porque a mitologia, "como relato das fundações, das origens remotas, das instaurações, das edificações primeiras” (LAPOUJADE, 2015, p. 85), permite substituir o fundamento “místico” (irrepresentável na ordem do discurso e, por isso, essencialmente violento) por uma ficção discursiva, narrativa mitológica.

Nesse sentido, Maria Rita Kehl (2015, p. 371) nos lembra do exemplo do "mito de fundação da cultura" (e, de certo modo, do direito) que Freud imagina em Totem e Tabu, em que os filhos, ao eliminarem o pai autoritário e, com ele, a simples lei do mais forte, precisam instituir uma figura totêmica do pai “que preservasse a dimensão imaginária do poder e da ordem - qualquer ordem; uma lei simbólica que organizasse as trocas e a economia do gozo entre os irmãos”. Lapoujade (2015, p. 85) argumenta que a função do mythos e a do logos, no fundo, são a mesma, ainda que cada um a desempenhe à sua maneira. Trata-se da função de estabelecer uma certa ordem a partir de um certo discurso, de instituir “um espaço de ordem no qual a violência vira sinônimo de desordem”. Daí a pertinência do apontamento de Jeanne-Marie Gagnebin (2011, p. 9), de que a contraposição do mythos ao logos, de tradição grega, não é tão pertinente ao ensaio de Benjamin quanto a contraposição entre mito e história, de tradição judaica. A autora escreve que a crítica de Benjamin à violência “mítica” pode ser lida como “a crítica de uma concepção de vida e de destino que sempre ameaça, sob formas diversas, as tentativas humanas de agir histórica e livremente”. Afinal, voltando a Lapoujade (2015, 
p. 85), a “instauração mitológica” estabelece uma situação em que “cada um de nós está sempre já despojado do seu poder”. Ecoando a interpretação de Butler da lenda de Níobe, o autor escreve que “contraímos uma dívida antes mesmo de nascer, uma dívida de existência que faz com que sejamos sempre devedores, já desapossados ${ }^{6}$. Estamos no registro da dívida infinita com a violência primeira fundadora”. Exposta a estrutura "mítica” da justificação da violência, cabe a pergunta de Lapoujade (2015, p. 82): Será que só as sociedades antigas têm mitos? Ou “não é esta, de fato, a mitologia própria das sociedades civilizadas?”

\subsection{UM CENÁRIO INQUIETANTE}

Gostaria, aqui, de voltar a Butler, já que ela fornece uma das formulações mais claras e compreensivas da violência “mítica” em Para uma Crítica da Violência:

A violência mítica estabelece o direito sem nenhuma justificação para fazê-lo, e é apenas uma vez estabelecido o direito que podemos sequer começar a falar sobre justificação. Crucialmente, o direito é instituído sem justificação, sem referência à justificação, porém torna a referência à justificação possível como consequência dessa instituição. Primeiro o sujeito é vinculado [bound] pelo direito, e só então o enquadramento [framework] jurídico emerge para justificar o caráter vinculante do direito. Como consequência, sujeitos são produzidos que são responsáveis diante do direito [to the law and before the law], que passam a definir-se em função da sua relação com essa responsabilidade jurídica. (BUTLER, 2006, p. 203)

Essa passagem sintetiza boa parte do que foi discutido no presente capítulo. Trata-se de um cenário inquietante. A fundação “mística” do direito se dá por um golpe de força. Esse golpe não tem razão nem lei, nem mesmo linguagem que o explique, mas logra apresentar-se como justificado après coup na medida em que é ele que institui as técnicas de interpretação que o produzirão como legítimo. Sua violência física e retórica originária é escondida, assim, por um mito justificante. Ademais, a captura do vivente por essa rede de dispositivos não é produzida após, mas ao mesmo tempo que, ou mesmo (logicamente) antes da própria estrutura que organiza esses dispositivos (AGAMBEN, 2009). Ela não é justificada por essa estrutura, e sim sua condição de possibilidade. Nesse quadro, tanto o par meios/fins quanto a distinção decorrente entre violência instituinte e mantenedora do direito distinções em torno das quais a violência legítima é produzida - mostram-se como mecanismos internos de uma máquina cuja única finalidade é reiterar seu funcionamento. Cada peça parece conectar-se à outra em um ciclo de captura e justificação, sem que nenhum fim externo o justifique.

\footnotetext{
${ }^{6}$ Em linha semelhante, Kehl (2015, p. 373) explica que, no mito da fundação totêmica, “o que a lei institui, na inauguração da nossa vida subjetiva, é a impossibilidade de retorno do infans (que ainda não é um sujeito) à totalidade (simbolizada pelo corpo materno) da qual o nascimento já o separou. A lei, em psicanálise, é o princípio que institui a separação entre o infans e a experiência da totalidade (uterina), a que chamamos de gozo. Essa separação é condição da emergência do sujeito, que para a psicanálise é sempre um ser de falta.”
} 
O vivente se mostra preso nesse ciclo, sem, contudo, ter qualquer poder sobre ele, já que é enquadrado como sujeito pelas suas formas. Esse vivente sujeito ao direito, pelo menos da forma que o vemos agora, parece desprovido de liberdade ou de agência histórica, já que o âmbito das práticas disponíveis a ele está sempre já determinado pela mesma instituição que o constituiu, por meio de diversos dispositivos, como sujeito. Aí está a "luz problemática” (BENJAMIN, 2011, p. 148) sob a qual a violência do direito passa a mostrar-se para Benjamin, na medida em que a "violência imediata nas manifestações míticas [se mostra] aparentada, ou mesmo idêntica, à violência instauradora do direito", da mesma forma que a violência mantenedora do direito "por ela representada" (BENJAMIN, 2011, p. 155). A dialética entre a violência instituinte e a violência mantenedora do direito, governada por seus próprios mecanismos e tendo como fim a própria reiteração, passa a assemelhar-se a um câncer em metástase descontrolada, uma fera colérica ou uma máquina automatizada que se liberta do controle humano. Com efeito, se Benjamin (2011, p. 144) escreve que a violência colérica "é comparável muito menos a uma máquina, que para quando o foguista a abandona do que a uma fera que, logo que o domador lhe dá as costas, enlouquece desvairadamente”, é porque escreve em uma época do avanço da técnica em que uma máquina dependeria “do foguista” para manter-se funcionando. Hoje, a metáfora da fera e a da máquina parecem igualmente pertinentes. Tanto é assim que Duarte (2015, p. 72) descreve a violência contemporânea como "fruto do [...] desenvolvimento monstruoso da técnica que sobrepujou o homem, pois ela não serve mais a ele, como tradicionalmente. Ele é que serve a ela, engatado numa engrenagem que não pode parar, pois o movimento sem fim (sem telos) é sua lei tácita”. A violência "mítica” como destino ou pura manifestação da cólera não se rege pela relação entre meios e fins, isto é, não se relaciona de nenhuma forma com a sua própria justificação. Essa é a "lei dos seus meios”, o mecanismo interno que rege o seu movimento de reiteração, aquele que, para Benjamin (2011, p. 144), é o único critério válido segundo o qual a violência de uma ação pode ser julgada.

Em seu ensaio "Violência na mudança e mudança na violência”, Duarte escreve que, se o homem pode ser dito violento, ele "o é na medida em que colide com uma ordem estática ou repetitivamente cíclica.” O autor faz uma recapitulação das formas como a violência foi percebida através das eras históricas. A violência, na antiguidade, estaria atrelada a “paixões tristes” (DUARTE, 2015, p. 72), já que a ordem natural era vista como perene, e violento seria aquilo que perturbasse essa ordem natural. Já na modernidade, a história passa a ser pensada como "uma chance para o homem erguer-se por suas próprias forças até a perfeição futura” (DUARTE, 2015, p. 64), de modo que “o significado da violência, associado ao da mudança”, se torna “eminentemente criativo” e atrelado a “paixões alegres” (DUARTE, 2015, p. 72). Duarte (2015, p. 66) menciona Marx, que não 
deixava de reconhecer no seu tempo a existência de violências instituídas e mantenedoras da ordem presente, mas que dava maior importância à violência revolucionária: "se aquelas são positivas, ou seja, confirmam os dados positivamente existentes da sociedade, esta é uma potência negativa, ou seja, uma força que criticamente negará tais condições instituídas”. "O clarão da história”, para modernos como Marx, “depende da ruptura que o presente faz com o passado para o futuro emergir”.

Já na era contemporânea, passa a predominar a violência “desapaixonada, banalmente técnica” (DUARTE, 2015, p. 72) aqui discutida, engrenagem sem telos que, contudo, representa "a última e mais formidável forma de dominação” (ARENDT, 1970, p. 38). Duarte remete a essa passagem de Arendt para apresentar "a burocracia, ou o domínio de um sistema intrincado de departamentos nos quais nenhum homem [...] pode ser tomado como responsável, e que deveria mais propriamente chamar-se domínio de Ninguém [rule by Nobody]” (ARENDT, 1970, p. 38) como estágio atual e inquietante da violência. Duarte (2015, p. 73) explica que "se a teoria política tradicional definira a tirania como um governo que não presta contas sobre si mesmo, o domínio abstrato da técnica no qual os sujeitos desaparecem é tirânico”. Nesse quadro, a arena política parece desaparecer, "reduzida ao gerenciamento competente da sociedade e à administração da vida" (DUARTE, 2015, p. 75). Daí certos lapsos de discurso interessantes, como quando o governador de São Paulo, Geraldo Alckmin, sobre as ocupações de escolas que vinham obstruindo o andar natural das coisas (violentas, portanto, ainda que não fisicamente) como forma de oposição à chamada reorganização do ensino estadual, disse, em tom de denúncia, que havia ali "uma nítida ação política” (ROSSI, 2015). Pois é evidente que havia. Mas é que a política, em tempos de gerenciamento técnico do vivente, parece ter se tornado sinônimo de violência e, por isso, palavrão. Duarte resume a questão da seguinte forma:

O ponto é que, no horizonte da técnica, tudo não passa de fundo de reserva ou de energia para alimentar a sua própria engrenagem, o seu próprio processo - que apenas ideologicamente ainda recebe o nome de progresso, pois perdeu o horizonte de futuro ao qual estaria destinado, ficando sem telos, sem objetivo que não seja o de se manter funcionando. (DUARTE, 2015, p. 76)

Em seu ensaio para o ciclo “Mutações: fontes passionais da violência”, Olgária Matos (2015) recorda o que talvez seja um dos grandes paradigmas para a violência viciosa aqui discutida. Em Aushwitz, ao perguntar a um soldado por que não lhe era permitido saciar a sede com a neve do chão, Primo Levi ouve como resposta: “Hier ist kein warum” (“Aqui não há porquê”). Esse paradigma encontra eco em versão menos grave, até mesmo risível (foi dito que a história se repete primeiro como tragédia, depois como farsa), em uma situação que acabou virando meme nas redes sociais do Brasil de 2013. A Polícia Militar do Distrito Federal tinha estabelecido uma linha a não ser cruzada 
pelos participantes de uma manifestação que tentava se aproximar do Congresso Nacional. A linha foi respeitada, e ainda assim um capitão foi filmado borrifando spray de pimenta contra os manifestantes. Quando indagado sobre a justificativa do ato, ele responde - e essa foi a frase que virou meme - “porque eu quis”. “Aqui não há porquê”, ou então “porque eu quis” - assim se expressa a violência do destino, que não aparece como legítima nem ilegítima, e sim se desloca em um espaço em que a questão da justificação (ou da ausência dela) se torna indiferente.

\section{CONCLUSÃO}

Se a violência mediante a qual se institui e se mantém o direito, especialmente nas situações mais críticas, funciona como um círculo vicioso; se ela reproduz a si mesma como máquina de gestão técnica do vivente, como estancar tal violência? Como redescobrir um pensamento da política, da responsabilidade e da mudança, em um cenário que parece cancelar todos esses domínios? Pelo menos no cenário disposto por Duarte, parece que seria necessário redescobrir uma violência de tipo moderno, que permitisse romper com as formas do presente e dar andamento à história. Lapoujade (2015, p. 93) escreve, em ensaio justaposto ao de Duarte, que "certas violências devem ser vistas como extremamente preciosas, pois elas constituem verdadeiras forças de oposição, as únicas capazes de engendrar novos discursos e instaurar - talvez - os novos direitos, modos de organização e modos de existência do amanhã”. O autor ressalta, porém, que "a verdadeira violência vem sempre de fora” (LAPOUJADE, 2015, p. 86). Ele explica que, no âmbito do mito como relato das fundações, não só o tempo é moldado, mas também o espaço, na medida em que o soberano que reina deve distribuir, cercar, demarcar e delimitar as fronteiras de sua terra. De forma que lembra Schmitt, Lapoujade escreve que "o limite define aqui a forma de interioridade do Estado, a extensão da sua forma de soberania, na medida em que esta desempenha seu papel separador; ela separa o interior do exterior”. A “verdadeira violência”, nesse quadro, deveria não apenas vir de fora, mas manifestar-se como “destruição positiva, no sentido de que derruba os limites” (LAPOUJADE, 2015, p. 87).

Benjamin (2011, p. 150) termina por condenar de forma bastante direta todo poder jurídico como violência “mítica”. Para ele, “a manifestação mítica da violência imediata mostra-se, em seu núcleo mais profundo, idêntica a toda violência do direito”. Essa observação “transforma a suspeita quanto ao caráter problemático dessa violência em certeza quanto ao caráter pernicioso de sua função histórica, tornando tarefa a sua abolição”. Ainda na mesma passagem, Benjamin começa a esboçar o projeto da suplantação dessa violência, que mais cedo ele tinha sugerido ao afirmar que "impõe-se a pergunta se existem outras modalidades de violência” (BENJAMIN, 2011, p. 145) além daquelas

Revista da Faculdade de Direito - UFPR, Curitiba, vol. 61, n. 3, set./dez. 2016, p. 299 - 321 
consideradas por toda filosofia do direito, isto é, pela positivista e pela jusnaturalista, que só eram capazes de pensar a violência como meio voltado a fins. $\mathrm{O}$ autor escreve que a tarefa de abolir a violência do direito "suscita, em última instância, [...] a questão de uma violência pura, imediata, que possa estancar a marcha da violência mítica” (BENJAMIN, 2011, p. 150), que venha romper o “círculo atado magicamente nas formas míticas do direito” (BENJAMIN, 2011, p. 115), o “movimento dialético" entre a violência instituinte e a mantenedora do direito.

A partir desse problema, impõe-se a questão das possibilidades de pensar o direito para além do direito, de uma forma que recupere o espaço para uma ação histórica, transformadora e responsável em relação a ele. Se a esperança de Benjamin está ligada a uma violência pura, absolutamente externa e absolutamente destruidora do direito, que venha trazer uma solução redentora ao problema da violência, em Derrida há uma grande desconfiança com relação à possibilidade dessa redenção. Não havendo espaço, aqui, para encarar esse desafio teórico, contentamo-nos por ora em delimitá-lo.

\section{REFERÊNCIAS}

AGAMBEN, Giorgio. Estado de exceção. São Paulo: Boitempo, 2004.

. O que é o contemporâneo? e outros ensaios. Chapecó: Argos, 2009.

ARENDT, Hannah. On Violence. New York: Harvest/HBJ, 1970.

BENJAMIN, Walter. Escritos sobre mito e linguagem. São Paulo: Editora 34, 2011.

BUTLER, Judith. CONFERENNCIA MAGNA COM JUDITH BUTLER |9/9 [2015] das 16h às 18h | I Seminário Queer [original]. Disponível em: <https://goo.gl/DTVU3H>. Acesso em: 5 fev. 2016.

Critique, Coersion and Sacred Life in Benjamin's “Critique of Violence”. In: DE VRIES, Hent (Ed.). Political Theologies: Public Religions in a Post-Secular World. New York: Fordham University Press, 2006.

DERRIDA, Jacques. De la Grammatologie. Paris: Éditions de Minuit, 1967a.

. Force de Loi: Le “fondement mystique de l’autorité”. Paris: Galilée, 2005.

. L'écriture et la Différence. Paris: Éditions du Seuil, 1967b.

. Marges de la Philosophie. Paris: Éditions de Minuit, 1972.

Préjugés: Devant la loi. In: DERRIDA, Jacques et al. La Faculté de Juger. Paris: Éditions de Minuit, 1985.

DUARTE, Pedro. Violência na mudança e mudança na violência. In: NOVAES, Adauto (Org.). 
Mutações: fontes passionais da violência. São Paulo: Sesc, 2015, p. 59-78.

DWORKIN, Ronald. Taking Rights Seriously. Cambridge: Harvard University Press, 1978.

FERREIRA, Natália Damazio Pinto. Testemunhas do esquecimento: uma análise do auto de resistência a partir do estado de exceção e da vida nua. 2013. Dissertação (Mestrado em Direito) Universidade do Estado do Rio de Janeiro, Rio de Janeiro, 2013.

GAGNEBIN, Jeanne-Marie. Apresentação. In: BENJAMIN, Walter. Escritos sobre mito $e$ linguagem. São Paulo: Editora 34, 2011.

GOHN, Maria da Glória. Manifestações de junho de 2013 no Brasil e as praças dos indignados no Mundo. Petrópolis: Vozes, 2014.

GROS, Frédéric. A ética da obediência. In: NOVAES, Adauto (Org.). Mutações: fontes passionais da violência. São Paulo: Sesc, 2015, p. 221-236.

HART, H. L. A. The Concept of Law. Oxford: Clarendon Press, 1994.

KAHN, Tulio. A segurança pública e as manifestações de junho de 2013. In: FIGUEIREDO, Rubens (Org.). Junho de 2013: a sociedade enfrenta o Estado. São Paulo: Summus, 2014, p. 115-132.

KEHL, Maria Rita. Violência do pai, violência dos irmãos. In: NOVAES, Adauto (Org.). Mutações: fontes passionais da violência. São Paulo: Sesc, 2015, p. 371-386.

LAPOUJADE, David. Fundar a violência: uma mitologia? In: NOVAES, Adauto (Org.). Mutações: fontes passionais da violência. São Paulo: Sesc, 2015, p. 79-94.

MATOS, Olgária. A Guerra de Troia não acontecerá: pathos antigo e tecnologia moderna. In: NOVAES, Adauto (Org.). Mutações: fontes passionais da violência. São Paulo: Sesc, 2015, p. 237270.

PELLEGRINI, Marcelo. Violência: Brasil mata 82 jovens por dia. Carta Capital. Santana do Parnaíba, 4/12/2014. Disponível em: <https://goo.gl/A4dvvA>. Acesso em: 5 abr. 2016.

ROSSI, Marina. Ocupação de 182 escolas em SP vira teste de resistência de Alckmin. El País. 28 nov. 2015. Disponível em: <https://goo.gl/Yc4YZF>. Acesso em: 5 fev. 2016.

ŽIŽEK, Slavoj. Violence: Six sideways reflections. New York: Picador, 2008.

\title{
A MACHINE FOR GRINDING PEOPLE: THE PROBLEM OF THE AMBIGUOUS RELATION BETWEEN LAW AND VIOLENCE
}

\begin{abstract}
The goal of this paper is to show, mainly through the work of Walter Benjamin and Jacques Derrida, a certain ambiguity in the relation between the concepts of law and violence, and to pose it as a problem, yet the solution to this problem is not to be reached in this paper, needing to be developed
\end{abstract}

Revista da Faculdade de Direito - UFPR, Curitiba, vol. 61, n. 3, set./dez. 2016, p. 299 - 321 
elsewhere. First we will present the concept of violence as problematic, distinguishing it from other issues such as power and force. Through Benjamin, we will present the distinction between means and ends as thought by legal positivism and natural law, as well as the distinction established by the author between the violence that institutes law and the one which maintains it. We will exemplify those questions through a brief discussion of the police institution and of the "autos de resistência". Next, we will show the reasons why Benjamin ends up condemning legal power, seeing in it a vicious circularity, in light of which it shows itself as an immediate manifestation of violence, called by the author "mythic" violence. We will end this paper with a brief suggestion about the possibility of thinking a solution to the established problem.

\section{KEYWORDS}

Jacques Derrida. Walter Benjamin. Violence. Autos de resistência. 